\title{
Quantitative genetic architecture of parasite-induced cataract in rainbow trout, Oncorhynchus mykiss
}

\author{
H Kuukka-Anttila ${ }^{1,2}$, N Peuhkuri ${ }^{2}$, I Kolari ${ }^{3}$, T Paananen ${ }^{4}$ and A Kause ${ }^{5}$ \\ ${ }^{1}$ Department of Biological and Environmental Sciences, University of Helsinki, Helsinki, Finland; ${ }^{2}$ Finnish Game and Fisheries Research \\ Institute (FGFRI), Helsinki, Finland; ${ }^{3}$ FGFRI, Enonkoski, Finland; ${ }^{4}$ FGFRI, Tervo, Finland and ${ }^{5}$ MTT Agrifood Research Finland, \\ Biotechnology and Food Research, Biometrical Genetics, Jokioinen, Finland
}

\begin{abstract}
Parasites impose costs on their hosts. The capability to fight against them is of great advantage, but may also be traded off with other traits. Although often observed at the phenotypic level, our knowledge of the extent to which such trade-offs are genetically determined is relatively poor. We tested this possibility with a farmed rainbow trout population suffering from natural Diplostomum spp. infections that cause cataracts in fish. We estimated the heritability of cataract severity and examined phenotypic and genetic correlations between cataract and a set of performance traits measured three times during a 3 -year rearing period. A cataract score was used as an indicator of the host's capability to resist and/or tolerate the parasite. Our results showed moderate heritability for the cataract. Nevertheless, we found no evidence for a genetic or phenotypic trade-off between parasite resistance/tolerance and the
\end{abstract}

Keywords: Rainbow trout; cataract; Diplostomum; heritability; parasitism; trade-off

\section{Introduction}

Parasite resistance can be regarded as one prerequisite for a successful life history because parasites are often costly to their hosts. The costs of parasitism are typically observed, for instance, as altered behaviour (Crowden and Broom, 1980; Barber et al., 2000), an increased predation risk (Seppälä et al., 2004), decreased fertility (Riley and Chappell, 1992), reduced growth (Chappell et al., 1994) and ultimately, as death (Lester, 1977; Brassard et al., 1982). Hosts have therefore evolved a wide array of adaptations to resist parasites. However, parasite resistance can also incur physiological costs because resources needed for resistance cannot be allocated to other important functions, such as growth and reproduction (reviewed by Sheldon and Verhulst, 1996; Norris and Evans, 2000). Individuals also potentially vary in their capability to tolerate the physiological costs of the infection (Brown and Handley, 2006). When the costs of parasitism are expressed as genetic (co)var-

Correspondence: H Kuukka-Anttila, FGFRI, PO Box 2, FI-00791 Helsinki, Finland.

E-mail: hanna.kuukka@helsinki.fi

Received 20 September 2008; revised 29 April 2009; accepted 13

August 2009; published online 23 September 2009 measured performance traits. Initial body weight was not correlated with the cataract score. Phenotypic and genetic correlations of cataract severity with body mass and condition measured in the second and third year were strongly negative, indicating reduced growth and condition in fish with a high cataract score. The reduced body size and condition in cataract-bearing fish were probably reflected in the phenotypic association between a high cataract score and delayed maturity age in females. Put together, our study did not provide evidence of genetic or phenotypic trade-offs between Diplostomum resistance/tolerance and a number of performance traits. Therefore, selection for lessened Diplostomum-caused cataracts is unlikely to have a negative impact on the studied performance traits.

Heredity (2010) 104, 20-27; doi:10.1038/hdy.2009.123; published online 23 September 2009 iation for the traits, they contribute to the evolutionary trajectory of multitrait evolution.

Genetic variation in a trait allows adaptation in response to selection and is thus of great importance for population persistence in a changing environment. However, natural selection is expected to erode genetic variation in fitness-related traits, leading to low heritability of these traits (Fisher, 1930; Mousseau and Roff, 1987). Studies on various organisms have shown genetic variation in parasite resistance (for example, Carius et al., 2001; Råberg et al., 2007 and references therein). In fish, genetic variation in parasite resistance has also been shown (Ballabeni and Ward, 1993; Barber et al., 2001), but the actual heritability of resistance and thus its potential to respond to selection has rarely been reported (but see Glover et al., 2005; Kolstad et al., 2005). In terrestrial farm animals, a moderate heritability for parasite resistance has been shown (Coltman et al., 2001).

The maintenance of heritable variation for resistance may result from the costs of resistance (Luong and Polak, 2007), leading to genetic trade-offs between resistance and other fitness-related traits (Sheldon and Verhulst, 1996). A gene (antagonistic pleiotropy), or a set of linked genes (linkage disequilibrium), having a favourable effect on one trait and an unfavourable effect on another trait, forms the genetic basis for such trade-offs. 
Consequently, the traits would not be expected to evolve independently from each other. It has been shown that in fish, parasite resistance is traded off, for instance, with growth (Barber et al., 2001), sexual ornamentation (Skarstein and Folstad, 1996) or sperm quality (Liljedal et al., 1999). These effects, however, have usually been observed at the phenotypic level and very few studies have examined the genetic correlations between resistance and other fitness-related traits (Coltman et al., 2001). To be able to assess genetic constraints on life-history evolution, estimates of genetic correlations are needed.

Here, using rainbow trout, Oncorhynchus mykiss (Walbaum), we first estimated the heritability of cataract formation following an infection by the eye fluke, Diplostomum spp. (Helminth, Trematoda). The Diplostomum spp. impairs vision by causing opaqueness, that is, cataracts, in the lens of the fish eye. We were specifically interested in Diplostomum spp. because the rainbow trout were naturally and heavily infected with it and we predicted that the problems caused by this parasite could be reduced by selection. The direct cost of Diplostomum spp. infection, that is, cataract severity, could be due to parasite resistance (the amount of parasites capable to infest an eye for a given exposure) and potentially also due to tolerance (the ability of a fish to buffer the negative effects of parasites in the eye), and thus a term resistance/tolerance is used here from now on. Second, to increase understanding of the way resistance/tolerance potentially co-evolves with other traits, we estimated phenotypic and genetic correlations between cataract severity and a number of performance traits (body weight, condition, age at maturity and mortality). These traits are potentially influenced by resource allocation to resistance, which may lead to trade-offs (Stearns, 1989). Third, we aimed to clarify the relationship between carotenoids and parasite resistance/tolerance. Carotenoids are deposited in the flesh and give the orange colour in the family Salmonidae. Owing to their antioxidant and immune-enhancing activity they also provide the physiological mechanism for a potential relationship between resistance/tolerance and flesh colour (Christiansen et al., 1995). Because carotenoids deposited in flesh or skin are away from immunological functions (Blount, 2004) we investigated whether there is a trade-off between carotenoid allocation to flesh colouration and cataract severity.

\section{Materials and methods}

\section{Study fish}

The study population of rainbow trout originated from a selection programme run by the Finnish Game and Fisheries Research Institute and MTT Agrifood Research Finland at Tervo Aquaculture station (nucleus) in central Finland. The population was established in the late 1980s, and fish are currently selected for rapid growth, age of maturity, skin and flesh colour and body shape. Selection and management procedures have been described in detail by Kause et al. (2005).

\section{Mating design and rearing procedure}

The parents of the experimental fish were mated using a partial factorial mating design, where each sire was mated on average with 2.0. dams and each dam was mated on average with 2.2 sires (Table 1). To generate a total of 341 families, fertilizations with 168 sires and 155 dams were completed within two days in April 2003. Eggs were incubated in a single incubator, and family identification was maintained by dividing incubation trays into subsections. At the eyed-egg stage in June, fish were transferred to 150-1 indoor family-specific tanks. At an approximate weight of $50 \mathrm{~g}$ in October-February, fish were individually tagged using passive integrated transponders (Trovan Ltd., Munich, Germany). During tagging, each family was divided into three groups, one group to be reared at the nucleus and two groups at two sea stations.

To maximize genetic gain at the nucleus, within-family selection was practiced during tagging by leaving the largest fish within a family at the nucleus and transferring the second largest ones to the two sea stations (Martinez et al., 2006). The remaining untagged fish within a family were weighed as a group $(w)$, counted $(n)$ and culled. To include these fish in the data, a total of $n$ fish, each with a tagging weight of $w / n$, were generated for each family. On average, 60 (range 47-65) individuals were individually weighed and tagged from each family, whereas data were generated for 89 (range 5-149) untagged fish per family.

In April 2004, the two groups per family were transferred to two sea stations in SW Finland. At both stations, the fish were reared in a single net pen and managed following the commercial practices of the farm. The group maintained at the nucleus was reared in a single ground-bottomed outdoor raceway $(5 \times 50 \times$ $1.5 \mathrm{~m}$ ) supplied with freshwater. Throughout the cultivation, the fish were fed ad libitum with commercial pellet feed (Raisio group, Raisio, Finland).

At the two sea stations, fish were reared for one additional growing season until November 2004 (station 1) and January 2005 (station 2). At the nucleus, fish were reared for two additional seasons, until October 2005. An effective growing season in Finland lasts from late April to November.

\section{Trait measurements}

Fish were measured either at the freshwater nucleus or seawater stations for a total of seven traits of interest on three occasions: after one growing season during tagging (time 1), after the second growing season (time 2) and after the third growing season (time 3, freshwater only). The recording time point is indicated in the Results section as a subscript for a trait.

At the nucleus station, the following traits were recorded. Time 1: body mass and condition factor. Time 2: cataract severity, blindness, body mass, condition factor, age of maturity and mortality. Time 3: body mass, condition factor, age of maturity and mortality. At the two sea stations, age of maturity and fillet colour were assessed at time 2. In the genetic analysis, the sea stations were included as a fixed sea station effect, removing its effect on a trait variation. Sample sizes for the studied traits are given in Table 1.

The presence and severity of cataracts was recorded using a KOWA sl-15 slit lamp microscope (Kowa Ltd. Tokyo, Japan) following the 0-4 categorization by Wall and Bjerkås (1999). In addition, a score of 5 was used to 
Table 1 Sample sizes $(n)$, means and s.d. for traits measured in rainbow trout

\begin{tabular}{|c|c|c|c|c|c|c|}
\hline Variable & $\mathrm{n}$ & Mean \pm s.d. & $n$ sires & $n$ dams & $n$ fams & Family size mean (min-max) \\
\hline Cataract $_{2}$ & 696 & $7.50 \pm 0.93$ & 168 & 155 & 341 & $2.4(1-7)$ \\
\hline Blindness $_{2}$ & 7207 & $0.11 \pm 0.38$ & 168 & 155 & 341 & $21.1(3-29)$ \\
\hline Mass $_{1}$ & 50827 & $54.36 \pm 21.42$ & 168 & 155 & 341 & $149.1(52-209)$ \\
\hline $\operatorname{Mass}_{2}$ & 7202 & $734.19 \pm 186.24$ & 168 & 155 & 341 & $21.1(3-29)$ \\
\hline $\mathrm{Mass}_{3}$ & 6037 & $2243.86 \pm 430.31$ & 168 & 155 & 341 & $17.7(2-27)$ \\
\hline Condition factor $_{1}$ & 20387 & $0 \pm 0.08$ & 168 & 155 & 341 & $59.8(47-65)$ \\
\hline 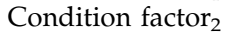 & 7202 & $0 \pm 0.11$ & 168 & 155 & 341 & $21.1(3-29)$ \\
\hline Condition factor $_{3}$ & 4313 & $0 \pm 0.10$ & 168 & 155 & 341 & $12.7(2-24)$ \\
\hline Fillet colour sea 2 & 1958 & $28.27 \pm 0.03$ & 168 & 155 & 341 & $5.8(1-13)$ \\
\hline Male maturity 2 & 2549 & $0.09 \pm 0.029$ & 168 & 155 & 341 & $7.6(1-17)$ \\
\hline Male maturity sea 2 & 1540 & $0.20 \pm 0.40$ & 168 & 155 & 339 & $4.6(1-11)$ \\
\hline Female maturity $_{3}$ & 3753 & $0.53 \pm 0.50$ & 168 & 155 & 341 & $11.0(2-20)$ \\
\hline Mortality $_{2}$ & 10240 & $0.29 \pm 0.46$ & 168 & 155 & 341 & $30.0(29-34)$ \\
\hline Mortality $_{3}$ & 6669 & $0.09 \pm 0.29$ & 168 & 155 & 341 & $19.6(2-28)$ \\
\hline
\end{tabular}

Number of sires ( $n$ sires), dams ( $n$ dams) and full-sib families ( $n$ fams), and mean family size are also given. The subscript indicates the measurement time for the trait.

code for fully injured eyes, where the normal eye anatomy could not be seen. Cataract scores from the right and left eye were summed to obtain a single cataract value for each individual for the analysis. In addition, a simple and rapid macroscopic eye examination was carried out for all the fish in the breeding programme by a trained person. The resulting variable was termed 'blindness' and was scored as 0 (healthy eyes), 1 (one eye opaque) or 2 (both eyes opaque). Diplostomun flukes were the only macroscopically visible parasites observed during the handling and slaughter of these fish. No signs of viral or bacterial infections were noticed.

Residuals of the II type regression between body mass and body length were calculated and used as values of individuals' condition factor (Green, 2001).

Ages at maturity of male and female fish were treated as two separate traits (see Kause et al., 2005). To record the stage of maturity of live fish at the freshwater nucleus, the gonads were scanned through the skin using an ultra-sound device (485 Anser Vet with a $7.5 \mathrm{MHz}$ linear array probe; Pie Medical, Maastricht, The Netherlands) to obtain an image. At sea, the maturity stage was visually identified from the gonads of gutted fish. For male age at maturity in freshwater, the 2-year-old mature males were scored as 1 and the maturing 3-year-old males as 0 . For female maturity in freshwater, a score of 1 was given for the maturing 3year-old females and a score of 0 for immature, latermaturing individuals. For male maturity at sea, mature males were scored as 1 and immature males as 0 . Female maturity could not be recorded at sea because they mature after the years of recording. Across the whole data set, five sex/maturity classes were identified: males mature at 2 or 3 years of age, females mature at 3 or more years and fish of unknown sex or age at maturity. To record mortality, a score of 0 was given for a live individual and 1 for a missing one at a recording time point. Fillet colour at sea was measured using the Roché colour reference card (Skrede et al., 1990).

To record traits at the nucleus station, the fish were anaesthetized with buffered MS-222 (tricaine methane sulphonate). At the sea stations, the traits were recorded after the fish were killed. The fish were handled following the Finnish legislation for using animals in research (permission no. 12/05).

\section{Genetic analysis}

Pedigree information from the year 1989 onwards was used in the analysis. Multivariate mixed animal models with restricted maximum likelihood methodology in DMUAI software (Jensen and Madsen, 2000) were used to estimate heritabilities $\left(h^{2}\right)$ as well as phenotypic $\left(r_{\mathrm{P}}\right)$ and genetic $\left(r_{\mathrm{G}}\right)$ correlations between the traits. The animal models used for different traits are presented in Table 2.

In animal breeding data sets, it is typical that selection based on a single or several traits is practiced from generation to generation and during data collection within a cohort. This has two consequences. First, genetic parameters are specific for the artificially selected population and do not reflect those of natural populations. Second, if non-random phenotypic recording is not accounted for in the statistical analysis, genetic parameters of the selected traits and the traits correlated with these traits are biased. In this study, the pre-selection of the fish at tagging was accounted for in the genetic analysis to eliminate biases in the (co)variance components (Pollak et al., 1984; Ouweltjes et al., 1988). We included the (tagging) mass of all the fish $(n=50827)$, including those transferred to the sea stations, those left at the nucleus station and those removed from the programme, always as a trait in all multitrait analyses. In this way, the software recognizes that fish at 2 and 3 years of age are not a random sample of a family. This allows the estimation of expected trait values at the age of 2 and 3 years also for the fish culled at the age of 1 year, correcting for the sampling bias (Pollak et al., 1984; Ouweltjes et al., 1988).

Heritabilities $\left(h^{2}=V_{\mathrm{G}} / V_{\mathrm{P}}\right)$ and full-sib effect ratios $\left(c^{2}=V_{\mathrm{FS}} / V_{\mathrm{P}}\right)$, in which $V_{\mathrm{G}}$ is genetic variance due to the animal effect, $V_{\mathrm{FS}}$ is variance due to the full-sib family effect and $V_{\mathrm{P}}$ is phenotypic variance, were calculated for all the recorded traits. The full-sib effect was modelled without pedigree information, and it includes effects due to the common rearing of full-sibs from incubation until tagging, as well as parts of potential dominance effects and maternal, including maternal genetic effects. The full-sib effect was excluded from the model when it explained less than $2 \%$ of the total variance. Heritabilities of binary traits, coded as 0 or 1 , were transformed to the underlying normally distributed liability scale following 
Table 2 Animal models used for investigating the heritabilities $\left(h^{2}\right)$ as well as phenotypic $\left(r_{\mathrm{P}}\right)$ and genetic $\left(r_{\mathrm{G}}\right)$ correlations between traits measured in rainbow trout

\begin{tabular}{|c|c|c|c|c|c|c|}
\hline Trait $^{\mathrm{a}}$ & animal $_{i}$ & FSeffect & $S_{E X M A T_{k}}$ & $S E X_{l}$ & $S_{S A S T A T}$ & POP MEAN \\
\hline Cataract $_{2}{ }^{\mathrm{b}}$ & $x$ & & & $x$ & & \\
\hline Blindness $_{2}{ }^{b}$ & $x$ & & & $x$ & & \\
\hline $\operatorname{Mass}_{1}{ }^{\mathrm{c}}$ & $x$ & $x$ & $x$ & & & \\
\hline Mass $_{2}$ & $x$ & $x$ & $x$ & & & \\
\hline $\mathrm{Mass}_{3}$ & $x$ & $x$ & $x$ & & & \\
\hline Mass sea $_{2}$ & $x$ & $x$ & & & $x$ & \\
\hline Condition factor ${ }_{1}{ }^{c}$ & $x$ & $x$ & $x$ & & & \\
\hline Condition factor $_{2}$ & $x$ & & $x$ & & & \\
\hline Condition factor $_{3}$ & $x$ & & $x$ & & & \\
\hline Fillet colour sea ${ }_{2}{ }^{d}$ & $x$ & & $x$ & & $x$ & \\
\hline Male maturity 2 & $x$ & $x$ & & & & $x$ \\
\hline Male maturity sea 2 & $x$ & $x$ & & & $x$ & \\
\hline Female maturity $_{3}$ & $x$ & $x$ & & & & $x$ \\
\hline Mortality $_{2}$ & $x$ & $x$ & & & & $x$ \\
\hline Mortality $_{3}$ & $x$ & $x$ & & & & $x$ \\
\hline
\end{tabular}

Animal ${ }_{i}$ : random pedigree effect for an individual $i=$ number of observations.

FSeffect $t_{j}$ : random full-sib effect $j=$ number of full-sib families.

$\mathrm{SEXMAT}_{\mathrm{k}}$ : fixed effect for sex and maturity classes $k=1-5$ (male, female, mature, immature, maturity not known).

SEX : fixed sex effect $l=1-3$ (males, females, sex unknown).

SEASTAT $_{\mathrm{m}}$ : fixed effect of the two sea stations, $m=1,2$.

${ }^{a}$ Within-family selection based on Mass $_{1}$ was practiced at time 1 . Thus, Mass ${ }_{1}$ was always included as a trait in multitrait analyses. In this way, REML corrects the records of all traits to a random sample, and genetic parameters for all the traits will not be biased by the selection.

${ }^{b}$ Because cataract formation secondarily postpones maturity, maturity in the analysis for cataract c and blindness $_{2}$ would diminish their genetic variation. Thus, $\mathrm{SEX}_{1}$ was used in the model instead of SEXMAT .

${ }^{\mathrm{C}}$ For mass 1 , a covariate of the cumulative temperature sum at the date of tagging mass recording was also used in the model.

${ }^{d}$ SEXMAT was excluded in the analysis when calculating the correlation between male age at maturity and fillet colour at sea.

Dempster and Lerner (1950). When two traits were measured from different animals (for example, fresh and seawater traits), residual correlation was set to zero because it does not exist.

\section{Results}

All the 969 screened individuals had cataracts in their eyes. Cataracts were severe, with the average score being 7.50 ( \pm s.d. 0.93 , range $4-10$ ).

\section{Genetic variation}

Heritability estimates for the studied characters are presented in Table 3. For cataract ${ }_{2}$ and blindness ${ }_{2}$, heritability was of a moderate degree. Body mass and the condition factor showed high heritabilities at all three measuring points. The full-sib effect for body weight and the condition factor was high only at measurement time one, and marginal at times two and three, suggesting that in the initial phase both maternal and common environmental effects had a role. Both male and female age at maturity had moderate heritabilities. For mortality, heritability was low at both measurement times. Heritability of the fillet colour 2 was low.

\section{Phenotypic and genetic correlations}

The phenotypic correlation between cataract $_{2}$ and blindness $_{2}$ was moderately positive and the genetic correlation highly positive (Table 4). This is of methodological interest due to the simplicity and ease of recording blindness rather than the more sophisticated but more laborious use of the split-lamp. Owing to the high genetic correlation between the two traits, blindness 2 was discarded from the latter analysis.
Table 3 Heritabilities $\left(h^{2}\right)$, full-sib effect ratio $\left(c^{2}\right)$ and phenotypic variances $\left(V_{P}\right)$ for the traits measured in rainbow trout

\begin{tabular}{|c|c|c|c|c|c|c|}
\hline Trait & $h^{2}$ & s.e. & $\mathrm{P}$ & $c^{2}$ & s.e. & $V_{P}$ \\
\hline Cataract $_{2}$ & 0.35 & 0.09 & $*$ & 一 & - & 0.864 \\
\hline Blindness $_{1}$ & 0.21 & .03 & $*$ & - & - & 0.146 \\
\hline Mass $_{1}$ & 0.41 & 0.08 & $*$ & 0.24 & 0.04 & 185 \\
\hline Mass $_{2}$ & 0.41 & 0.05 & $*$ & 0.02 & 0.01 & 32562 \\
\hline $\mathrm{Mass}_{3}$ & 0.48 & 0.05 & $*$ & 0.02 & 0.01 & 167648 \\
\hline Condition factor $_{1}$ & 0.47 & 0.09 & $*$ & 0.21 & 0.04 & 0.006 \\
\hline tion factor $_{2}$ & 0.55 & 0.04 & $*$ & - & - & 0.014 \\
\hline Condition factor $_{3}$ & 0.65 & 0.05 & $*$ & - & - & 0.009 \\
\hline Fillet colour sea 2 & 0.09 & 0.03 & $*$ & - & - & 1.289 \\
\hline Male $\mathrm{r}$ & $0.17(0.5$ & 0.05 & $*$ & 0.05 & 0.02 & 0.087 \\
\hline Male maturity sea 2 & $0.34(0.694)$ & $0.08(0.16)$ & $*$ & 0.03 & 0.03 & 0.158 \\
\hline Female maturity $_{3}$ & $0.29(0.453)$ & $0.05(0.08)$ & * & 0.05 & 0.02 & 0.258 \\
\hline Mortality $_{2}$ & $0.19(0.33)$ & $0.04(0.07)$ & * & 0.05 & 0.01 & 0.180 \\
\hline Mortality $_{3}$ & $0.12(0.369)$ & $0.03(0.09)$ & * & 0.05 & 0.01 & 0.082 \\
\hline
\end{tabular}

The subscript indicates the measurement time of the trait. Liability scale heritabilities and their s.e. for binary traits are given in parentheses.

*Zero not within $1 \times$ s.e. of a heritability.

Cataract $_{2}$ displayed weak negative phenotypic and

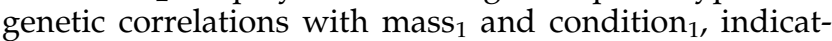
ing that early growth and condition were only weakly related to cataract severity recorded later on (Table 4). In contrast, phenotypic correlations of cataract ${ }_{2}$ with mass $_{2}$ and mass $_{3}$ were moderately and genetic correlations strongly negative, showing that increased cataract severity was related to reduced body mass. The negative phenotypic correlations of cataract $_{2}$ with condition $_{2}$ and condition $_{3}$ were weak but the negative genetic correlations moderate (Table 4). 
Table 4 Phenotypic $\left(r_{\mathrm{P}}\right)$ and genetic $\left(r_{\mathrm{G}} \pm\right.$ s.e. $)$ correlations between the traits measured in rainbow trout. The subscript indicates the measurement time for the trait

\begin{tabular}{|c|c|c|}
\hline Trait combination & $r_{P}$ & $r_{G} \pm$ s.e. \\
\hline Cataract $_{2 \_}$blindness $_{2}$ & 0.21 & $0.764 \pm 0.11$ \\
\hline Cataract $_{2}-$ mass $_{1}$ & -0.09 & $-0.080 \pm 0.17$ \\
\hline Cataract $_{2}-$ mass $_{2}$ & -0.35 & $-0.640 \pm 0.10$ \\
\hline Cataract $_{2}$ - mass $_{3}$ & -0.37 & $-0.715 \pm 0.10$ \\
\hline Cataract $_{2}$ - condition factor $_{1}$ & -0.18 & $-0.197 \pm 0.16$ \\
\hline Cataract $_{2}-$ condition $_{\text {factor }}$ & -0.12 & $-0.371 \pm 0.13$ \\
\hline Cataract $_{2}$ - ${\text { condition } \text { factor }_{3}}$ & -0.16 & $-0.332 \pm 0.13$ \\
\hline Cataract $_{2}$-female maturity 3 & -0.15 & $-0.269 \pm 0.15$ \\
\hline Cataract $_{2}$-male maturity & -0.01 & $0.030 \pm 0.19$ \\
\hline Cataract $_{2}-$ mortality $_{2}$ & - & $-0.132 \pm 0.16$ \\
\hline Cataract $_{2}-$ mortality $_{3}$ & -0.03 & $-0.085 \pm 0.18$ \\
\hline Cataract $_{2}$-fillet colour sea & - & $0.171 \pm 0.23$ \\
\hline Male maturity sea 2 -fillet colour sea 2 & -0.38 & $-0.052 \pm 0.21$ \\
\hline
\end{tabular}

*Zero not within $1.96 \times$ s.e. of a genetic correlation.

Cataract severity was related to the age at maturity in females but not in males (Table 4). There was a moderate negative phenotypic correlation between cataract $_{2}$ and female age at maturity, indicating that the females with cataracts matured later than the healthier eyed ones. The genetic correlation was also negative but did not reach significance. However, the age at maturity of males was not related to cataract 2 at phenotypic or genetic levels. Cataract $_{2}$ was not related to individual mortality either (Table 4).

The genetic correlation of cataract 2 with fillet colour 2 was low (Table 4), and thus did not indicate a link between fillet carotenoids and parasite defence. Male maturity and fillet colour at sea showed a moderate negative phenotypic, but not a genetic correlation, indicating that the late-maturing males had more colourful fillets (Table 4).

\section{Discussion}

Diplostomum spp. eye flukes can have a severe impact on their fish host population by reducing the visual capacity of the hosts and thus their foraging and anti-predatory performance (Owen et al., 1993; Seppälä et al., 2004). Our results show that the susceptibility to cataracts induced by Diplostomum spp. has a moderate heritability $\left(h^{2}=\right.$ $0.35)$ within a farmed rainbow trout population. Given that the Diplostomum load in rainbow trout eyes has been found to be directly related to the cataract score (Karvonen et al., 2004; Seppänen et al., 2008), our findings suggests that part of the variation in Diplostomum resistance/tolerance within our study population is determined by genetic factors. To the best of our knowledge, this is the first study on the quantitative genetics of fish cataracts caused by Diplostomum spp. and it indicates that Diplostomum resistance/tolerance, and thereby the severity of cataracts, is prone to evolutionary change when either natural or artificial selection acts upon it. If severe cataracts lower the fitness of an individual fish, this should be followed by a genetic increase in resistance against cataracts and/or in tolerance to cataracts at the population level.

The vertebrate immune response includes an innate and an acquired component (Janeway et al., 1999). Although we cannot discount the effects of physical and behavioural differences such as swimming speed and feeding behaviour, the existence of genetic variation in cataract severity suggests that innate resistance, genetic control of acquired resistance and/or tolerance potentially have a role in the susceptibility of rainbow trout to Diplostomum spp. infection. Heritable resistance against helminths is well documented in sheep (Eady et al., 2003). In fish, Karvonen et al. (2005) showed that innate immunity has little or no role in Diplostomum infection in rainbow trout. They found that over $80 \%$ of the experimentally presented $D$. spathaceum cercariae were established in the lenses of naive fish. In fish that were infected second time, acquired resistance decreased the establishment of cercariae by $85-89 \%$. In contrast, Kalbe and Kurtz (2006), working on three-spined sticklebacks, Gasterosteus aculeatus, found no evidence of a significant decrease in D. pseudospathaceum infection after a previous exposure to the parasite.

Despite the potential for a trade-off between Diplostomum resistance/tolerance and growth, the current results revealed neither a phenotypic nor a genetic trade-off between growth and the cataract score. Our study showed weak phenotypic and genetic correlations between the cataract score and the initial body mass at the first measurement, when the average fish weight was $50 \mathrm{~g}$. Accordingly, higher cataract score was not related to slower initial growth. There was no evidence of a tradeoff between cataract severity and growth at older ages, either. Instead, the opposite was observed. Phenotypic and genetic correlations of cataract severity with mass and condition factor in the two later samplings (at $c a$. $734 \mathrm{~g}$ and $\mathrm{ca} .2245 \mathrm{~g}$ of body weight) were strongly negative. In other words, the heavier the fish were at the time of eye checking and also later on, the smaller were the cataracts in their eyes. Given the absence of the genetic trade-off between cataracts and growth, the continuous selection for rapid growth is not expected to make fish more genetically prone to cataracts. A similar trend was seen for the correlations of body condition with cataract severity. This is logical because rapid growth is typically phenotypically and genetically related to increased body condition (Kause et al., 2003). Similar to our study, in sheep, genetic correlations between nematode resistance and growth are mostly favourable (Pollott et al., 2004), but unfavourable genetic trade-offs have been observed especially in young animals (Bisset et al., 1992). In contrast to our study, though, genetic trade-offs have been observed between resistance against mastitis causing pathogens and milk production in cows (Lund et al., 1999).

Cataract frequency displays extensive annual variation in our study population, and is strongly influenced by management practices of a farm (personal observation). The high incidence of cataracts in this study likely results because these practices such as gull nets have not been implemented in our population until now.

The lack of a relationship between initial growth (before the first body mass measurement) and later cataracts suggests that there are no obvious maintenance costs of immune function that would be reflected as a cost in reduced growth. Because of the early rearing in regularly cleaned indoor plastic tanks with much lower parasite exposure than in outdoor ground-bottomed raceways, and also because of the young age and thus undeveloped cataracts leading to reduced eyesight and 
consequently to less efficient feeding, it is likely that Diplostomum infection or cataract formation had not influenced fish growth at the first measurement time. Consequently, the maintenance costs of resistance/ tolerance, if any, should have been detected at the initial growth stage.

The distinct negative relationship between the cataract score and subsequent body masses suggests that cataract development is followed by impaired growth. This has been reported to be the case in fish suffering from nonparasitic cataracts (Ersdal et al., 2001). Similarly, Seppänen et al. (2008) showed a significant phenotypic relationship in landlocked Atlantic salmon, Salmo salar, between parasitism and individual growth $(r=-0.376$, $n=50$ fish, $P<0.01$ ), such that fish with a higher parasite load and more severe cataracts suffered from reduced growth. However, a vision-mediated reduction in the weight increment may not be the only explanation for the observed relationship between cataract severity and body size. It is also possible that a third trait related to both susceptibility to Diplostomum infection and body size can generate the negative relationship. Behaviour, for example, is a potential candidate for such trait. If there were differences, for example, in the spatial distribution of large (fast growing) and small (slow growing) fish, they might be exposed to a differential risk of Diplostomum infection. Fish swimming in the upper water body will probably face fewer parasites released from bottom-detached snails than fish swimming in lower water body. Although our results do not imply costs of resistance or tolerance we cannot totally exclude the possibility that the negative impact of cataract formation on growth caused directly by reduced eyesight (Ersdal et al., 2001) is masking the potential costs of resistance or tolerance on growth.

Although there was a distinct relationship between the severity of cataracts and body mass and condition at the final two sampling times, our results showed no relationship between the cataract score and mortality. At least three factors may explain this result. Firstly, it is possible that cataracts caused some deaths in our study, but that other causes of death masked the impact. Mortality did show moderate heritability and was probably affected by some other inherent factor(s) and/ or diseases. Survival is typically a composite trait influenced by multiple underlying factors, causing great temporal and spatial variation in the expression of its genetic variation and of its relation with other traits (Vehviläinen et al., 2008). Second, cataracts may not have been severe enough to cause death under the benign farming conditions where predation was absent and food was offered ad libitum. Third, this result is perhaps not so surprising when considering the parasite's point of view. It is not beneficial for Diplostomum to kill its fish host because this would risk the transmission of the parasite to its definitive fish-eating bird host (Chappell et al., 1994). However, non-parasitic cataract as such has been shown to reduce survival in farmed salmon (Menzies et al., 2002).

Our results revealed that at the phenotypic level, females with more severe cataracts had postponed maturity. It is possible that, first, reduced growth or a lower condition in individuals with more severe cataracts led to a delay in maturity (Fleming, 1996). Second, given that the circadian rhythm is an essential stimulus in the maturation process (Duston and Bromage, 1986), the reproductive physiology of fish with severe cataracts may have been impaired because of the reduced perception of the light stimulus. Third, parasites might have directly influenced the host maturation process. Interestingly, there was neither phenotypic nor genetic relation between male maturity and cataract severity, even though physiological costs of spawning are well documented in male fish (Skarstein et al., 2001). Because reproduction in females requires considerable resources, the potential for a trade-off between growth, survival and reproduction is potentially greater than for males (Wootton, 1998). Moreover, it is likely that because male rainbow trout generally mature on average 1 year earlier than females (Kause et al., 2005), Diplostomum has less time to influence male maturation compared with that of females.

We also observed no genetic relationship between cataract severity and fillet colour. Carotenoids have an important role as antioxidants and immunostimulants (Skarstein and Folstad, 1996), as well as in ornament development in mature fish (Aksnes et al., 1986). However, our study design did not allow us to examine this phenomenon in enough detail. Ornament formation should also have been taken into account. This approach is also justified based on our results. In the studied fish there was a negative phenotypic relationship between male maturity and fillet colouration. This means that late-maturing males had more colourful flesh compared with their earlier-maturing counterparts. It is possible that early-maturing males had invested carotenoids in sexual ornamentation, as carotenoid-based pigments are important in sexual ornamentation (Olson and Owens, 1998). Interestingly, this relationship was not observed at the genetic level.

Given that fillet colour can be measured only destructively, the sea-reared sibs of the freshwater brood stock fish were used to record fillet colour. However, cataract severity was recorded from their sibs reared in freshwater. Because either fillet colour or cataract severity might display family re-ranking across environments, it is possible that an existent relation between the two traits may have been masked by the recording procedure in the current study. Nevertheless, genotype-by-environment interactions across production environments are typically weak (Kause et al., 2005).

In conclusion, our results showed that heritable genetic variation in cataract formation exists in rainbow trout. However, because of the lack of trade-offs between the studied traits and cataract formation, this variation may not be explained by negative genetic relationships among the studied traits. Instead, it is more probable that the dynamic host-parasite interactions maintain the heritability because the evolutionary change in parasites is likely to be more rapid than in their hosts (Hamilton and Zuk, 1982). Based on our results from rainbow trout, selection might increase parasite resistance/tolerance in farmed fish and thereby also reduce the frequency and severity of cataracts. The positive effects of selecting healthy eyed individuals would most probably also include faster growth. However, given that parasites rapidly adapt to their hosts (Dieter, 1994; Kaltz and Shykoff, 1998), there is a risk that selection will not guarantee an advantage. 


\section{Acknowledgements}

This study was financed by the Nordic Workgroup for Fisheries (NAF) as well as the Finnish Game and Fisheries Research Institute (HKA, NP, IK, TP) and MTT Agrifood Research Finland (AK). We thank the staff at the Tervo aquaculture station for all their help during the study.

\section{References}

Aksnes A, Gjerde B, Roald SO (1986). Biological, chemical and organoleptic changes during maturation of farmed Atlantic salmon, Salmo salar. Aquaculture 53: 7-20.

Ballabeni P, Ward PI (1993). Local adaptation of the tremadote Diplostomum phoxini to the European minnow Phoxinus phoxinus, its second intermediate host. Funct Ecol 7: 84-90.

Barber I, Arnott SA, Braithwaite WA, Andrew J, Huntingford FA (2001). Indirect fitness consequences of mate choice in sticklebacks: offspring of brighter males grow slowly but resist parasitic infections. Proc $R$ Soc Lond B Biol Sci 268: $71-76$.

Barber I, Arnott SA, Braithwaite WA, Andrew J, Mullen W, Huntingford FA (2000). Carotenoid-based sexual coloration and body condition in nesting male sticklebacks. J Fish Biol 57: 777-790.

Bisset SA, Vlassoff A, Morris CA, Southey BR, Baker RL, Parker AGH (1992). Heritability of and genetic correlations among fecal egg counts and productivity traits in Romney sheep. NZJ Agric Res 35: 51-58.

Blount JD (2004). Carotenoids and life-history evolution in animals. Arch Biochem Biophys 430: 10-15.

Brassard P, Rau ME, Curtis MA (1982). Infection dynamics of Diplostomum spathaceum cercariae and parasite-induced mortality of fish hosts. Parasitology 85: 489-493.

Brown JKM, Handley RJ (2006). Evolutionary genetics: Fight or flinch? Heredity 96: 3-4.

Carius H, Little TJ, Ebert D (2001). Genetic variation in a hostparasite association: potential for coevolution and frequencydependent selection. Evolution 55: 1136-1145.

Chappell LH, Hardie LJ, Secombes CJ (1994). Diplostomiasis: the disease and host-parasite interactions. In: Pike AW, Lewis JW (eds). Parasitic Diseases of Fish. Samara Publishing Limited: Great Britain. pp 59-86.

Coltman DW, Pilkington J, Kruuk LEB, Wilson K, Pemberton JM (2001). Positive genetic correlation between parasite resistance and body size in a free-living ungulate population. Evolution 55: 2116-2125.

Christiansen R, Glette J, Lie Ø, Torrissen OJ, Waagb $\varnothing$ R (1995). Antioxidant status and immunity in Atlantic salmon, Salmo salar L. fed semi-purified diets with and without astaxanthin supplementation. J Fish Dis 18: 317-328.

Crowden AE, Broom DM (1980). Effects of the eyefluke, Diplostomum spathaceum, on the behaviour of dace Leuciscus leuciscus. Anim Behav 28: 287-294.

Dempster ER, Lerner IM (1950). Heritability of threshold characters. Genetics 35: 212-236.

Dieter E (1994). Virulence and local adaptation of a horizontally transmitted parasite. Science 265: 1084-1086.

Duston J, Bromage N (1986). Photoperiodic mechanisms and rhythms of reproduction in the female rainbow trout. Fish Physiol Biochem 2: 35-51.

Eady SJ, Woolaston RR, Barger IA (2003). Comparison of genetic and nongenetic strategies for control of gastrointestinal nematodes of sheep. Livest Prod Sci 81: 11-23.

Ersdal C, Midtlyng PJ, Jarp J (2001). An epidemiological study of cataracts in seawater farmed Atlantic salmon Salmo salar. Dis Aquat Org 45: 229-236.

Fisher R (1930). The Genetical Theory of Natural Selection. Clarendon Press: Oxford, UK.
Fleming IA (1996). Reproductive strategies of Atlantic salmon: ecology and evolution. Rev Fish Biol Fish 6: 379-416.

Glover KA, Aasmundstad T, Nilsen F, Storset A, Skaala $\varnothing$ (2005). Variation of Atlantic salmon families Salmo salar L. in susceptibility to the sea lice Lepeophtheirus salmonis and Caligus elongatus. Aquaculture 245: 19-30.

Green AJ (2001). Mass/length residuals: Measures of body condition or generators of spurious results? Ecology 85: 1473-1483.

Hamilton WD, Zuk M (1982). Heritable true fitness and bright birds: a role for parasites? Science 218: 384-387.

Janeway CA, Travers P, Walport M, Capra JD (1999). Immunobiology: the Immune System in Health and Disease. Current Biology Publications: London.

Jensen I, Madsen P (2000). A User's Guide to DMU. A Package for Analysing Multivariate Mixed Models. National Institute of Animal Science, Research Center Foulum: Denmark.

Kalbe M, Kurtz J (2006). Local dierences in immunocompetence reect resistance of sticklebacks against the eye uke Diplostomum pseudospathaceum. Parasitology 132: 105-116.

Kaltz O, Shykoff JA (1998). Local adaptation in host-parasite systems. Heredity 81: 361-370.

Karvonen A, Seppälä O, Valtonen ET (2004). Eye fluke-induced cataract formation in fish: quantitative analysis using an opthalmological microscope. Parasitology 129: 473-478.

Karvonen A, Seppälä O, Valtonen ET (2005). Resistance against eye flukes: naïve versus previously infected fish. Parasitol Res 95: 55-59.

Kause A, Ritola O, Paananen T, Eskelinen U, Mäntysaari E (2003). Big and beautiful? Quantitative genetic parameters for appearance of large rainbow trouts. J Fish Biol 62: 610-622.

Kause A, Ritola O, Paananen T, Wahlroos H, Mäntysaari EA (2005). Genetic trends in growth, sexual maturity and skeletal deformations, and rate of inbreeding in a breeding programme for rainbow trout. Aquaculture 247: 177-187.

Kolstad K, Heuch PA, Gjerde B, Gjedrem T, Salte R (2005). Genetic variation in resistance of Atlantic salmon Salmo salar to the salmon louse Lepeophtheirus salmonis. Aquaculture 247: $145-151$.

Lester RJG (1977). An estimate of the mortality in a population of Perca flavencens owing to the Diplostomum adamsi. Can J Zool 55: 288-292.

Liljedal S, Folstad I, Skarstein F (1999). Secondary sex traits, parasites, immunity and ejaculate quality in the Arctic charr. Proc R Soc Lond B Biol Sci 266: 1893-1898.

Lund MS, Jensen J, Petersen PH (1999). Estimation of genetic and phenotypic parameters for clinical mastitis, somatic cell production deviance, and protein yield in dairy cattle using Gibbs sampling. I Dairy Sci 82: 1045-1051.

Luong LT, Polak M (2007). Environment-dependent trade-offs between ectoparasite resistance and larval competitive ability in the Drosophila-Macrocheles system. Heredity 99: 632-640.

Martinez V, Kause A, Mäntysaari EA, Mäki-Tanila A (2006). The use of alternative breeding schemes to enhance genetic improvement in rainbow trout: II. Two-stage selection. Aquaculture 254: 195-202.

Menzies FD, Crockford T, Breck O, Midtlyng PJ (2002). Estimation of direct costs associated with cataracts in farmed Atlantic salmon (Salmo salar). Bull Eur Ass Fish Pathol 22: 27-32.

Mousseau TA, Roff DA (1987). Natural selection and the heritability of fitness components. Heredity 59: 181-197.

Norris K, Evans MR (2000). Ecological immunology: life history trade-offs and immune defence in birds. Behav Ecol 11: 19-26.

Olson VA, Owens IPF (1998). Costly sexual signals: are carotenoids rare, risky or required? TREE 13: 510-514.

Owen SF, Barber I, Hart PJB (1993). Low-level infection by eye uke, Diplostomum spp., aects the vision of 3-spined sticklebacks, Gasterosteus aculeatus. J Fish Biol 42: 803-806. 
Ouweltjes W, Schaeffer LR, Kennedy BW (1988). Sensitivity of methods of variance component estimation to culling type of selection. J Dairy Sci 71: 773-779.

Pollak EJJ, Van der Werf J, Quaas RL (1984). Selection bias and multiple trait evaluation. J Dairy Sci 67: 1590-1595.

Pollott GE, Karlsson LJE, Eady S, Greeff JC (2004). Genetic parameters for indicators of host resistance to parasites from weaning to hogget age in Merino sheep. J Anim Sci 82: 2852-2864.

Riley EM, Chappell LH (1992). Effect of infection with Diplostomum spathaceum on the internal defence system of Lymnea stagnalis. J Invert Pathol 59: 3280-3283.

Råberg L, Sim D, Read AF (2007). Disentangling genetic variation for resistance and tolerance to infectious diseases in animals. Science 318: 812-814.

Seppälä O, Karvonen A, Valtonen ET (2004). Parasite-induced change in host behaviour and susceptibility to predation in an eye fluke-fish interaction. Anim Behav 68: 257-263.

Seppänen E, Kuukka H, Piironen J, Huuskonen H (2008). Relationship between standard metabolic rate and parasiteinduced cataract of juveniles in three Atlantic salmon stocks. J Fish Biol 72: 1659-1674.
Sheldon BC, Verhulst S (1996). Ecological immunology: costly parasite defences and trade-offs in evolutionary ecology. Trends Ecol Evol 11: 317-3221.

Skarstein F, Folstad I (1996). Sexual dichromatism and the immunocompetence handicap: an observational approach using Arctic charr. Oikos 76: 359-367.

Skarstein F, Folstad I, Liljedal S (2001). Whether to reproduce or not: immune suppression and costs of parasites during reproduction in the Arctic charr. Can J Zool 79: 271-278.

Skrede G, Risvik E, Huber M, Enerven G, Blumlein L (1990). Developing a color card for raw flesh of astaxanthin-fed salmon. J Food Sci 55: 356-363.

Stearns SC (1989). Trade-offs in life-history evolution. Func Ecol 3: $259-268$.

Wall T, Bjerkås E (1999). A simplified method of scoring cataracts in fish. Bull Eur Assoc Fish Pathol 19: 162-165.

Vehviläinen H, Kause A, Quinton C, Koskinen H, Paananen T 2008. Survival of the currently fittest-Genetics of rainbow trout survival across time and space. Genetics 180: 507-516.

Wootton RJ (ed) (1998). The Ecology of Teleost Fishes, 2nd edn. Kluwer academic publisher. Fish and fisheries series 24: Dordrecht, The Netherlands. 